\title{
CÉRIO (Ce) EM FERRICRETES NODULARES DESENVOLVIDOS EM SOLOS DA FORMAÇÃO ADAMANTINA ${ }^{1}$
}

\author{
Maurício Rizzato Coelho; Pablo Vidal-Torrado* \\ ${ }^{2}$ Centro de Solos e Recursos Agrombientais - IAC, C.P. 28 - CEP: 13020-900 - Campinas, SP. \\ ${ }^{3}$ Depto. de Solos e Nutrição de Plantas - USP/ESALQ, C.P. 9 - CEP: 13418-900 - Piracicaba, SP. \\ *Autor correspondente <pablo@carpa.ciagri.usp.br>
}

\begin{abstract}
RESUMO: O estudo de concentrações anômalas de elementos traço em ferricretes, como cério (Ce) e outros elementos das terras raras, tem apoiado discussões a respeito da gênese dessas feições em diferentes ambientes do planeta. No município de Pindorama (SP), no sopé de uma vertente com domínio de Argissolos Vermelho-Amarelos abrúpticos derivados do arenito cretácico da Formação Adamantina, Grupo Bauru (Ka), ocorrem horizontes ferricretes, cujas características e gênese são escassamente conhecidas, embora sejam de ocorrência comum na região norte do Estado de São Paulo. Procurou-se verificar a presença de concentrações de elementos terras raras nesses solos e assim poder fornecer subsídios para o conhecimento da gênese desses ferricretes, estudando-se um Argissolo Vermelho-Amarelo Eutrófico abrúptico plíntico dessa vertente. Após descrição morfológica do perfil, determinou-se a granulometria, bem como as concentrações de Fe e Mn totais (fluorescência de raios $\mathrm{X}$ ), extraídos por ataque sulfúrico, ditionito-citrato e por oxalato dos horizontes e dos nódulos encontrados. Em glébulas selecionadas, realizou-se estudos submicroscópicos e microanálises pontuais. Acumulações localizadas de $\mathrm{Ce}$ na forma de cerianita $\left(\mathrm{CeO}_{2}\right)$ foram encontradas apenas nos nódulos petroplínticos que apresentam revestimentos de óxidos de $\mathrm{Mn}$, situados na base do horizonte petroplíntico, e cuja gênese está associada ao rebaixamento definitivo do lençol freático. Cobalto (Co) também se concentra no interior dos nódulos ferro-manganíferos devido à ação co-precipitadora dos óxidos de manganês aí depositados.
\end{abstract}

Palavras-chave: laterita, petroplintita, plintita

\section{CERIUM (Ce) IN SOME NODULAR FERRICRETES DEVELOPED IN SOILS OF THE ADAMANTINA FORMATION}

\begin{abstract}
The observation of rare earth element (REE) accumulations, especially Ce, has led to an open discussion about the genesis of lateritic weathering systems. In the landscape of the northern State of São Paulo (Brazil), lateritic covers predominantly nodular exist in different topographic levels and, although not documented, constitute a feature that appears frequently on the slopes of Cretaceous sandstones of the Adamantina Formation (Ka). In order to obtain subsidies for the understanding of the genesis and the spatial distribution of these features, the objective of this research was to verify the presence and the form of occurrence of REE, in nodular ferricretes of an Eutric Plinthosol. Submicroscopic studies and microprobe analyses were performed on undeformed samples of Fe and Fe-Mn nodules. These were previously identified in morphological descriptions (macro and micro) of petroplinthic horizons located at the footslope of a toposequence. Cerium, iron and manganese were determined by $X$ ray fluorescence, and iron and manganese were also determined by selective dissolution. Localized accumulations of Ce were found only into petroplinthic nodules with $\mathrm{Mn}$ coatings, probably deposited during the definitive lowering of the water table. Ce and Co accompanied the mobilization and segregation of the $\mathrm{Mn}$ oxides and hydroxides due of the ability of these Mn species in concentrating and controlling the distribution of certain metallic ions.
\end{abstract}

Key words: laterite, petroplinthite, plinthite

\section{INTRODUÇÃO}

Dentre as terras raras, o cério $(\mathrm{Ce})$ é especialmente interessante nos estudos de pedogênese devido às suas peculiaridades sob condições naturais. $O$ elemento pode ocorrer na forma reduzida $\mathrm{Ce}^{3+}$ como a maioria dos lantanídeos, ou ainda, como $\mathrm{Ce}^{4+}$ em condições oxidantes, precipitando-se na forma de $\mathrm{CeO}_{2}$ a partir de soluções enriquecidas no elemento. $\mathrm{O}$ intemperismo de minerais primários, tais como micas e felsdspatos alcalinos, podem ser responsáveis pelo fornecimento de $\mathrm{Ce}^{3+}$ à solução do solo (Beauvais \& Roquin, 1996). O mineral aí formado pela precipitação de $\mathrm{Ce}^{3+}$ é a cerianita $\left(\mathrm{CeO}_{2}\right)$ e poucos são os relatos de sua ocorrência sob condições continentais (Braun et. al. 1990). Mais freqüentes são os estudos de nódulos de ferro e manganês em ambientes marinhos (Piper, 1974).

Variações do estado de oxidação em ambientes que passam de francamente redutores a oxidantes, costumam se dar associados à oscilação do lençol freático nos baixos níveis topográficos das paisagens tropicais, onde, a partir do forte intemperismo, acumula-se ferro e, 
as vezes, manganês na forma de nódulos e concreções. Esses horizontes são comumente denominados de lateríticos ou ferricretes. O termo ferricrete foi utilizado aqui para designar os depósitos ricos em ferro que são duros ou cimentados, sem ter necessariamente conotação genética (Bourman, 1993, Ollier, 1991 e Milnes et al., 1985). São nestes ambientes que acumulações de $\mathrm{Ce}$ foram descritas em perfis de intemperismo desenvolvidos sobre diferentes litologias: rochas ígneas básicas, alcalinas e ácidas na África tropical (Beauvais et al., 1990, Beauvais \& Roquin, 1996) e rochas alcalinas no Brasil são alguns dos exemplos citados na literatura (Braun et al. 1990, Roquin, 1990), sendo escassa as informações da presença de elementos do grupo das terras raras (ETR) em perfis ferricretes desenvolvidos de rochas sedimentares.

A constatação da acumulação de ETR, especialmente $\mathrm{Ce}$, tem apoiado as discussões sobre as condições dos sistemas de intemperismo lateríticos (Beauvais \& Colin, 1993; Beauvais \& Roquin, 1996 e Roquin, 1990).

Nas paisagens do norte do Estado de São Paulo, ferricretes nodulares existem em diferentes níveis topográficos e, apesar de pouco documentados, constituem feições, que se repetem com freqüência nas vertentes sobre os arenitos cretácicos da Formação Adamantina (Ka) do Grupo Bauru.

O objetivo do presente trabalho foi verificar a presença de cério e eventualmente outros ETR em ferricretes nodulares de um solo com B textural localizado no sopé de uma vertente sobre 0 arenito Adamantina, no Planalto Ocidental Paulista. Com isso, espera-se obter subsídios para o entendimento da gênese e distribuição desses materiais ferruginosos localizados nos baixos níveis topográficos da região estudada.

\section{MATERIAL E MÉTODOS}

O estudo foi conduzido na Estação Experimental de Pindorama do Instituto Agronômico (IAC), região norte do Estado de São Paulo, localizado próximo as coordenadas $21^{\circ} 13^{\prime}$ de latitude sul e $48^{\circ} 56^{\prime}$ de longitude oeste, com altitude média variando de 498 a 594 metros. O substrato rochoso pertence a Formação Adamantina (Grupo Bauru), datado do Cretáceo superior (Ka), o qual é caracterizado por bancos de arenitos de granulação fina a muito fina, alternados com lamitos, siltitos e arenitos lamíticos, sendo comum a ocorrência de cimento e nódulos carbonáticos (Soares et al., 1980).

O clima da região enquadra-se como Aw segundo Köppen, definido como tropical úmido com estação chuvosa no verão e seca no inverno, com precipitação média anual de 1390,3 $\mathrm{mm}$. A temperatura média dos três meses de verão (dezembro, janeiro e fevereiro) situa-se na faixa de $24,0^{\circ} \mathrm{C}$ e, de $19,5^{\circ} \mathrm{C}$, a média dos três meses de inverno (junho, julho e agosto).

Para este trabalho selecionou-se um perfil localizado no sopé de uma vertente (Figura 1) dominada por fei- ções plínticas, petroplínticas e mosqueados. Após descrição morfológica realizada em trincheira e seguindo especificações de Lemos \& Santos (1996), coletou-se amostras dos horizontes até a rocha semialterada. O perfil descrito foi classificado por Coelho (1998) como Podzólico Vermelho-amarelo, abrupto, pétrico, eutrófico, Tb, A moderado, textura arenosa/média ou Typic Plinthudult (Soil Survey Staff, 1994). O atual Sistema Brasileiro de Classificação dos Solos (EMPRESA BRASILEIRA DE PESQUISA AGROPECUÁRIA, 1999) enquadra-o como Argissolo Vermelho-Amarelo Eutrófico abrúptico plíntico A moderado textura arenosa/média.

No laboratório, as amostras de solo foram secas ao ar e passadas em peneira $\mathrm{n}^{\circ} 10$ (malha de $2 \mathrm{~mm}$ ) para análises químicas, granulométricas e de fluorescência de raios $\mathrm{X}$. Amostras provenientes dos horizontes ferricretes foram submetidas ao peneiramento por via úmida em peneira $n^{0} 10$ a fim de separar as glébulas da matriz interglebular. Posteriormente, as glébulas foram individualmente escovadas em água corrente para remoção do solo aderido, secas ao ar, trituradas em moinho mecânico e passadas em peneira $n^{0} \cdot 10$. A terra do horizonte ferricrete (matriz interglebular) foi seca ao ar e peneirada. Apenas o horizonte plíntico foi submetido aos procedimentos convencionais de preparo das amostras, ou seja, as glébulas e matriz foram suavemente homogeneizadas com martelo de borracha e passadas em peneira.

$\mathrm{Fe}, \mathrm{Mn}$ e Ce total foram determinados em amostras dos horizontes e glébulas do perfil por fluorescência de raios X em aparelho Philips PW 2400, utilizando-se amostras pulverizadas com granulometria inferior a 200 mesh e prensadas a $30 \mathrm{~T} \mathrm{~cm}^{-2}$ em $25 \%$ de cera. As concentrações de Fe e Mn foram calculadas através do método de Franzini et al. (1972). As concentrações de Ce foram obtidas através da correção por efeito Compton empregando-se 18 padrões internacionais. Os teores totais de $\mathrm{Fe}$ e $\mathrm{Mn}$ na fração argila foi obtido através do ataque com ácido sulfúrico, seguindo indicações de Vettori (1969) com algumas modificações proposta por Raij \& Valadares (1974). Utilizando-se os métodos preconizados por Buurman et al. (1996) para dissoluções seletivas, foram também determinadas as frações extraídas pelo ditionito-citrato ( $\mathrm{Fe}$ e Mn livres) e pelo oxalato-oxálico (Fe e Mn amorfos).

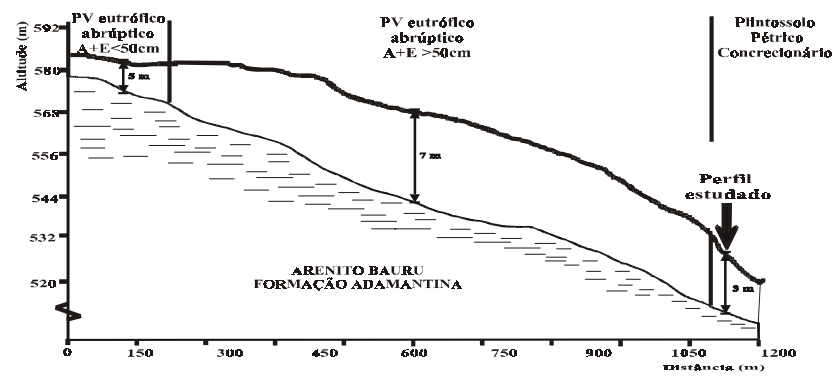

Figura 1 - Distribuição dos solos na paisagem e localização do perfil estudado. 
Após detalhado exame morfológico em lupa binocular estereoscópica e das seções delgadas em microscópio petrográfico, amostras indeformadas selecionadas dos principais tipos de glébulas foram submetidas ao exame em microscópio eletrônico de varredura marca JEOL modelo JSM - T330A, equipado com microssonda NORAN modelo TN 500. Para isso, amostras de aproximadamente $1 \mathrm{~cm}^{3}$ foram inicialmente nebulizadas com ouro e paládio e coladas em uma lâmina de vidro com cola de prata antes de serem introduzidas no tubo de vácuo do microscópio.

\section{RESULTADOS E DISCUSSÃO}

O perfil estudado apresenta a seqüência e morfologia de horizontes indicadas no TABELA 1 e na Figura 2. Dois horizontes ferricretes foram caracterizados seguidos aos horizontes texturais. O horizonte $\mathrm{F}$ é dominado por feições petroplínticas irregulares (Figura 3) de dimensões variando entre 0,3 a $10 \mathrm{~cm}$ e de colorações bruno-forte (7,5 YR 5/8) e vermelho-escuro-acizentado (10 R 3/3). Correspondem aos nódulos de Brewer (1976) e ocupam $80 \%$ do volume do horizonte. Alguns nódulos mostraram-se enegrecidos (2,5 YR 2,5/0) no seu interior, evidenciando uma maior segregação de manganês (Figura 3). Esses estão localizados predominantemente na base do horizonte e doravante serão referidos como nódulos manganíferos. O horizonte $\mathrm{Cf}(85-105 \mathrm{~cm})$ é plíntico, caracterizado por nódulos que ainda guardam a estrutura da rocha mãe. Ocupam $60 \%$ do volume do horizonte, são de formas irregulares, sendo que muitos dos quais assemelham-se aos fragmentos de rocha semidecomposta e ferruginizada (Figura 4). Suas dimensões variam desde 0,6 a 7,0 cm, com diâmetro médio de 3,0 $\mathrm{cm}$. Horizonte saprolítico $(\mathrm{Cr})$ predomina em seguida ao $\mathrm{Cf}$, com a rocha mãe aflorando a $164 \mathrm{~cm}$ de profundidade. A TABELA 1 mostra as propriedades granulométricas e os principais atributos morfológicos do perfil estudado.

No exame ao microscópio eletrônico de varredura (MEV) apenas os nódulos de Fe com revestimentos de $\mathrm{Mn}$ evidenciaram pequenos corpos de hábito glomerular na superfície do revestimento. A microanálise desses glomérulos demonstrou tratar-se de acumulações de $\mathrm{Ce}$ na forma de cerianita $\left(\mathrm{CeO}_{2}\right)$. Este é o principal mineral contendo $\mathrm{Ce}^{4+}$ e sua ocorrência tem sido pouco documentada na natureza (Braun, et al., 1990).

A Figura 5 evidencia o revestimento de manganês sobre um grão de quartzo no interior do nódulo manganífero petroplíntico. Nota-se a precipitação de cerianita (partículas com hábito glomerular e de coloração branca) distribuídas na superfície do "coating" de Mn e cuja história está associada a formação e evolução dos nódulos no perfil.

Através da MEV constatou-se ainda que as demais glébulas petroplínticas (Figura 3B) e plínticas (Figura 4) são formadas essencialmente por caulinita, hematita, goethita, gibbsita, mica e anatásio na fração argila, enquanto a fração areia é dominada por quartzo, alguns feldspatos potássicos, poucos sódicos e ilmenita, não mostrando nenhum tipo de ocorrência de terras raras.

TABELA 1 - Granulometria $^{(1)}$ e morfologia(2) do perfil estudado.

\begin{tabular}{|c|c|c|c|c|c|c|c|}
\hline \multirow[t]{2}{*}{ Horizonte ${ }^{(3)}$} & \multirow[t]{2}{*}{ Profundidade } & \multirow{2}{*}{$\begin{array}{c}\text { Cor } \\
\text { Munsell }\end{array}$} & \multicolumn{3}{|c|}{ Granulometria } & \multirow{2}{*}{$\begin{array}{c}\text { Estrutura } \\
\text { (tipo e grau) }\end{array}$} & \multirow[t]{2}{*}{ Nó dulos } \\
\hline & & & A. Total & Silte & Arg. & & \\
\hline & $\mathrm{m}$ & & -----------. & $-\mathrm{g} \mathrm{kg}^{-1}$ & - & & \\
\hline A & $0-0,1$ & 7,5YR4/2 & 810 & 100 & 80 & bl., médio, fraca. & $\begin{array}{c}\text { muito pouco, pequenos }(0,3 \\
\mathrm{cm}) \text {, duros, irreg.ulares, verm. } \\
\text { e ferr. }\end{array}$ \\
\hline$E$ & 0,26 & 7,5 YR 4/4 & 800 & 100 & 100 & bl. Médio. fraca. & Ídem \\
\hline Bt1 & 0,38 & 5 YR 4/6 & 660 & 90 & 250 & $\begin{array}{l}\text { bl. Médio/gr. } \\
\text { mod. }\end{array}$ & Ídem \\
\hline Bt2 & 0,60 & 5 YR 4/8 & 620 & 120 & 260 & $\begin{array}{l}\text { bl. Médio/gr. } \\
\text { mod. }\end{array}$ & $\begin{array}{c}\text { muito pouco, pequenos. }(0,35 \\
\mathrm{cm}) \text {, duros, irregulares., verm. } \\
\text { e ferr. }\end{array}$ \\
\hline $\mathrm{F}$ & 0,85 & 5 YR 4/6 & 580 & 110 & 320 & - & $\begin{array}{l}80 \% \text { nód. e } 20 \% \text { matriz. } \\
\text { Nódulos. petroplínticos.: } \\
\text { dominante, grande., duro, } \\
\text { irregulares, verm. e ferr. }\end{array}$ \\
\hline Cf & 1,10 & 5 YR 4/8 & 540 & 120 & 340 & - & $\begin{array}{l}60 \% \text { nód. e } 40 \% \text { matriz. } \\
\text { Nódulos plínticos: muito } \\
\text { freqüente., grandes., duros, } \\
\text { irregulares., verm.-amar. e ferr. }\end{array}$ \\
\hline $\mathrm{Cr}$ & 1,64 & 2,5 YR 4/6 & 440 & 140 & 32 & est. da rocha. & - \\
\hline $\mathrm{R}$ & 1,90 & 2,5 YR 4/6 & 520 & 300 & 17 & - & - \\
\hline
\end{tabular}

(1)A. Total: areia total; Arg.: argila; (2)amar.: amarelado; bl.: blocos subangulares; est.: estrutura; ferr.: ferruginoso; gr.: grande; mod.: moderado; verm.: vermelho; ${ }^{(3)} \mathrm{F}$ : matriz interglebular do horizonte F; Cf: amostra homogeneizada (plintita + matriz). 


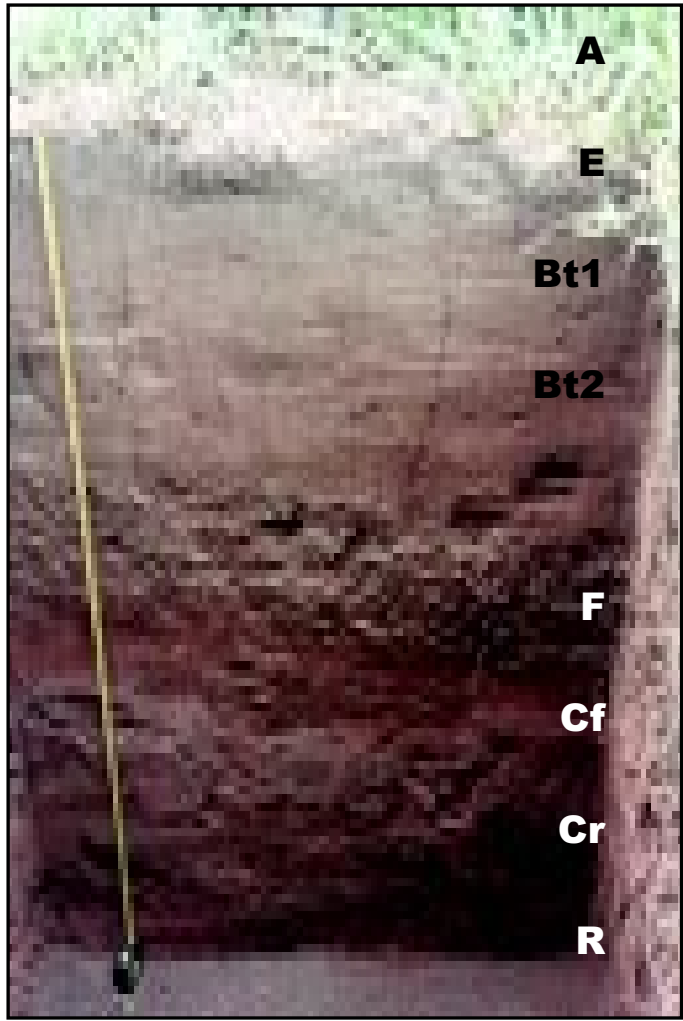

Figura 2 - Perfil estudado mostrando seus diferentes horizontes.
Coelho (1998), estudando a gênese e caracterização dos ferricretes nodulares em questão, identificou sua origem associada a oscilação do lençol freático, sendo que os aportes de ferro oriundos das posições mais elevadas da paisagem segregaram e precipitaram na superfície do lençol freático, originando os ferricretes de lençol nos baixos níveis topográficos, tal como encontrados hoje na região (Figuras 3 e 4). A TABELA 2 apresenta a distribuição do $\mathrm{Fe}$ e do $\mathrm{Mn}$ no perfil. Nota-se que os nódulos (F-N) predominantes no horizonte ferricrete são

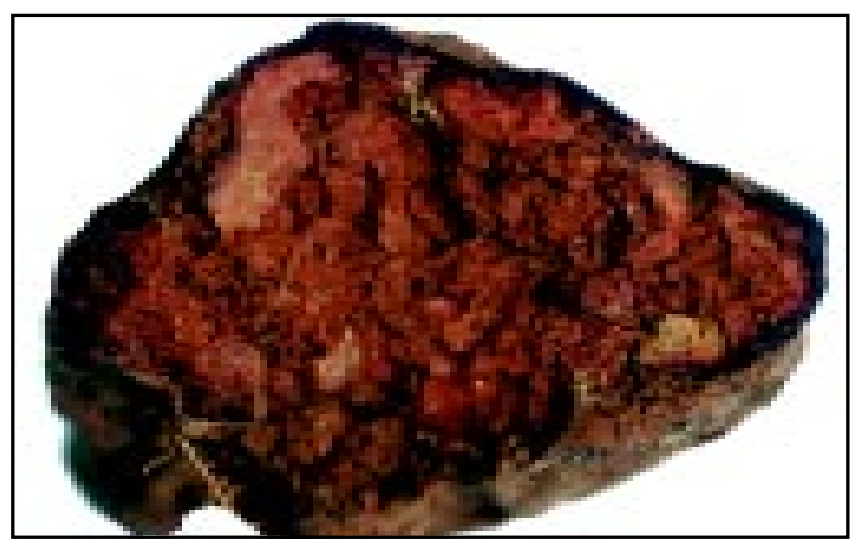

Figura 4 - Glébula plíntica (4 cm de diâmetro). Nota-se a preservação da estrutura da rocha e completa ausência de colorações enegrecidas no seu interior.

B)

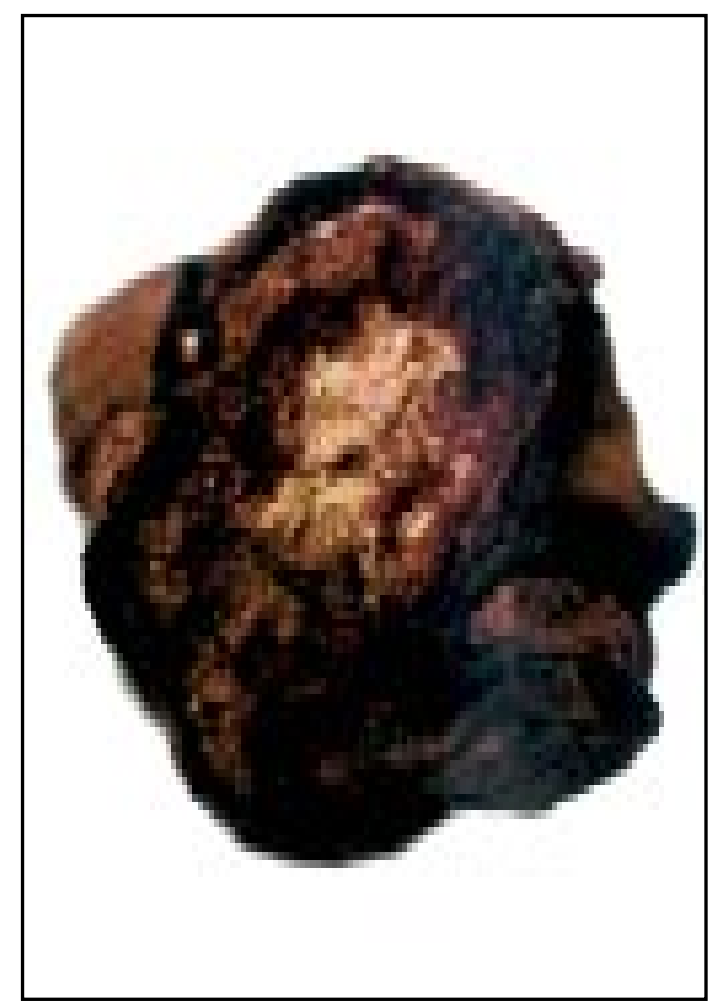

Figura 3 - A) Glébula petroplíntica com seu interior enegrecido devido à presença de manganês (2 cm de diâmetro). B) Glébula predominante no horizonte $\mathrm{F}$ (2, $5 \mathrm{~cm}$ de diâmetro). 
essencialmente ferruginosos, com uma pequena participação de manganês. Ambos, ferro e manganês, estão predominantemente na forma de óxidos cristalinos, o que pode ser verificado tanto observando a predominância desses elementos extraídos com ditionito em relação ao oxalato, como a proximidade entre os valores de $\mathrm{Fe}$ e $\mathrm{Mn}$ totais $\left(\mathrm{H}_{2} \mathrm{SO}_{4}\right.$ e $\left.\mathrm{FRX}\right)$ e aqueles extraídos pelo ditionito (DC). Essa caracterização química e mineralógica do Fe e do Mn no perfil, bem como a localização dos nódulos manganíferos na base do horizonte petroplíntico, constituem-se das principais evidências de sua gênese, e cujos mecanismos estão enunciados a seguir.

O manganês, elemento mais solúvel e móvel que o ferro, requer maiores potenciais de oxidação para precipitar (McKenzie, 1989). Com isso, espera-se que a deposição do elemento ocorra nos estágios finais de formação do horizonte petroplíntico, quando o nível do lençol freático encontra-se definitivamente rebaixado e maiores potenciais de oxidação prevalecerem, principalmente nos poros planares e canais de grande tamanho, preferencialmente preenchidos com ar (Bouma, 1983). Essas condições foram adequadas nos fragmentos de rocha parcialmente decompostos (saprolito). Uma posterior remobilização de $\mathrm{Fe}^{2+}$ favoreceu a precipitação do elemento nos locais de deposição de manganês, uma vez que o $\mathrm{Fe}^{2+}$ tende a se depositar também nos sítios onde manganês já existe (McKenzie, 1989), principalmente nos poros planares e canais, como citado acima. Devido ao menor teor de manganês em relação ao ferro no ambiente (TABELA 2), uma pequena e interrupta deposição do elemento é esperada. Assim, durante eventuais ciclos de saturação posteriores ao rebaixamento do lençol, possivelmente relacionados a uma hidromorfia suspensa condicionada pela descontinuidade de poros entre os horizontes superficiais e horizonte ferricrete, bem como a uma menor taxa de infiltração neste último horizonte, apenas $\mathrm{Fe}^{2+}$ é posteriormente remobilizado e precipitado ao redor das segregações iniciais de manganês e ferro, as quais atuaram como núcleo para as deposições ferruginosas sucessivas, encerrando o manganês no interior das glébulas ferruginosas, até evoluírem para a morfologia hoje encontrada no perfil. Essas glébulas manganíferas são as mais jovens do horizonte $F$ e seus mecanismos de formação explicam o fato de estarem localizadas apenas na base do horizonte ferricrete petroplíntico.

Como discutido anteriormente, a presença de cerianita não é comum em todas as glébulas estudadas. Sua ocorrência aparece como um fenômeno local e sempre associada a cobalto e manganês. Outros autores também identificaram essa mesma correlação entre os elementos e evidenciaram a segregação de minerais raros (cerianita) durante a ferruginização na gênese dos ferricretes (Beauvais \& Colin, 1993, Beauvais e Roquin, 1996, Beauvais et al., 1990, Roquin, 1990 e Taylor, 1968).
A fim de entender o comportamento do $\mathrm{Ce}$ sob diferentes condições de redox, podemos comparar $\mathrm{Ce}, \mathrm{Fe}$ e Mn. Para isso, o diagrama Eh-pH (Figura 6) permite uma explicação para os diferentes mecanismos envolvidos na gênese das glébulas manganíferas. Mantendo-se o pH constante e considerando-se seu valor médio nos solos intemperizados, nota-se pelo diagrama que a baixos
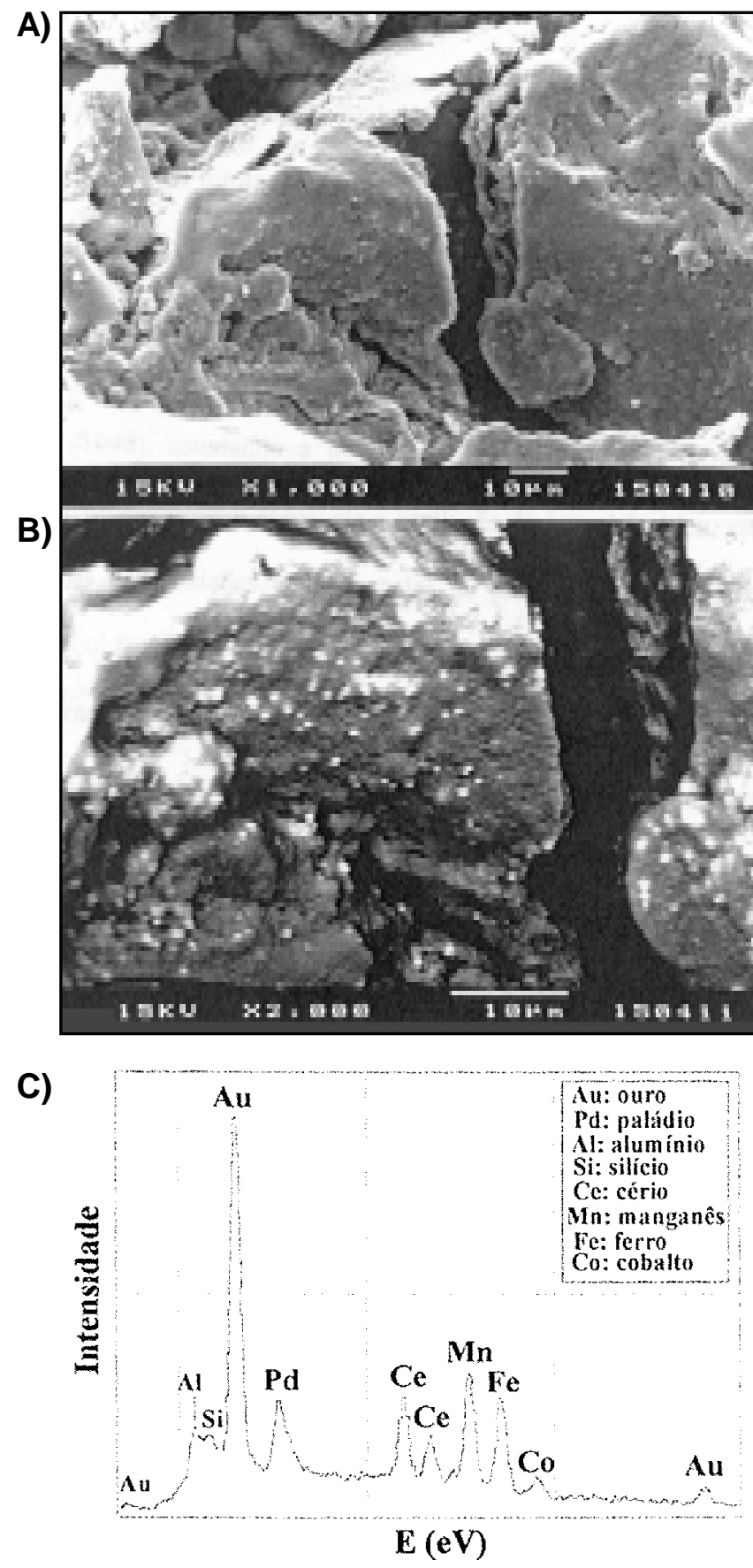

Figura 5 - A) Imagem de MEV do interior de um nódulo de Fe-Mn exibindo um revestimento de óxidos de manganês associado a cério e cobalto na superfície do grão de quartzo. B) Detalhe da foto anterior evidenciando a ocorrência de cerianita- $\mathrm{CeO}_{2}$ (pequenos corpos de hábito glomerular e de coloração branca). C) Análise química semi-quantitativa em espectro EDS do revestimento de manganês. 
valores de Eh (ponto A) os três elementos encontram-se na forma reduzida. A medida que 0 ambiente torna-se mais oxidante (ponto B), goethita é o primeiro mineral precipitado e representa parte dos minerais de óxidos e hidróxidos de ferro componentes dos ferricretes. Nessas condições a atividade do $\mathrm{Fe}^{2+}$ decresce ao passo que a atividade do $\mathrm{Ce}^{3+} \mathrm{e} \mathrm{Mn}^{2+}$ permanecem inalteradas.

A precipitação da goethita ocorre principalmente nas paredes dos macroporos fissurais e canais localizados no saprolito e imediatamente abaixo do horizonte ferricrete, onde maiores potenciais oxidantes prevalecem. A medida que o lençol freático é progressivamente rebaixado, os valores de Eh (ponto B) favorecem a mobilização de manganês dos locais mais elevados da paisagem e deposição abaixo do horizonte petroplíntico e nos macroporos fissurais e canais, os quais sofreram a precipitação inicial de ferro. As espécies reduzidas $\mathrm{Mn}^{2+} \mathrm{e}$ $\mathrm{Co}^{2+}$ tem campo de estabilidade similar (Figura 6), exigindo, dependendo da atividade desses íons na solução, valores relativamente mais elevados de Eh do que os necessários para a precipitação da cerianita. Entretanto, Co e Ce acompanharam a mobilização e segregação dos óxidos e hidróxidos de manganês, devido a habilidade desses minerais em concentrar e controlar a distribuição de certos íons metálicos (Taylor \& MacKenzie, 1966). Esta propriedade dos óxidos de $\mathrm{Mn}$ deriva da elevada eletronegatividade em valores de $\mathrm{pH}$ normais de solo (PCZ muito baixo), bem como de sua elevada superfície específica, conferindo-lhes alta capacidade de adsorção específica de cátions pouco hidratados (Mackenzie, 1989).

A distribuição do Ce no perfil mostrou os maiores valores no saprolito $(\mathrm{Cr})$, horizonte plíntico $(\mathrm{Cf})$ e rocha $(\mathrm{R})$, coincidindo com os maiores conteúdos de $\mathrm{Mn}$ obtidos por diferentes métodos (TABELA 2), evidenciando assim, a mobilização conjunta desses elementos da paisagem a montante e deposição na superfície dos fragmentos de saprolito e fendas da rocha, sob condições adequadas de
$\mathrm{pH}$ e potencial redox, tal como relatado anteriormente e sugerido como o principal mecanismo relacionado à gênese das glébulas manganíferas.

Com o progressivo aumento dos valores de Eh durante o rebaixamento do lençol (ponto $\mathrm{C}$ ), a precipitação do $\mathrm{Ce}^{3+}$ na forma de cerianita $\left(\mathrm{CeO}_{2}\right)$ é favorecida, originando os pequenos corpos de hábito glomerular, juntamente com o revestimento de $\mathrm{Mn}$, como apresentado na Figura 5. Nessas condições, a atividade do $\mathrm{Ce}^{3+} \mathrm{e} \mathrm{Mn}^{2+}$ é reduzida em solução. No entanto, pelo exame da mesma figura, os minerais de $\mathrm{Mn}$ aparentemente encontram-se amorfos no interior das glébulas manganíferas, como na maioria dos casos em que ocorrem concentrações de Mn em solos (MacKenzie, 1989), sugerindo ou que as condições de Eh e pH não foram adequadas à sua completa oxidação e formação de minerais cristalinos, ou que não houve tempo suficiente para cristalinizar-se. Essa pequena cristalinidade é confirmada pela similaridade na capacidade de extração que apresentam os extratores oxalato-oxálico e ditionito-citrato (Barral Silva, 1987) para o horizonte Cf, sendo que, a capacidade extratora do oxalato-oxálico sobrepôs-se ao efeito complexante e redutor do ditionito-citrato para o horizonte saprolítico e rocha, removendo maiores conteúdos de $\mathrm{Mn}$ de baixa cristalinidade. Embora o $\mathrm{Mn}$ apresenta-se predominantemente na forma cristalina para as glébulas petroplínticas (F-N), como pode ser analisado observandose a superioridade dos teores de Mn livre $\left(0,08 \mathrm{~g} \mathrm{~kg}^{-1}\right) \mathrm{em}$ relação ao Mn amorfo $\left(0,004 \mathrm{~g} \mathrm{~kg}^{-1}\right)$, pode-se argumentar que as petroplintitas ferruginosas são dominantes no horizonte $F$, perfazendo mais que $95 \%$ de seu volume. Essa preponderância associada a um procedimento de amostragem aleatória das glébulas no horizonte, foram responsáveis pela elevada cristalinidade dos óxidos de $\mathrm{Mn}$ nos nódulos, tal como relatado anteriormente, e favorecem a premissa de que a glébulas ferruginosas são mais maturas em relação às manganíferas.

TABELA 2 - Fe, Mn e Ce determinados no solo, saprolito, rocha e nódulos do perfil estudado.

\begin{tabular}{|c|c|c|c|c|c|c|c|c|c|c|}
\hline \multirow[t]{3}{*}{ Horizonte ${ }^{(1)}$} & \multirow[t]{2}{*}{ Profundidade } & \multicolumn{2}{|c|}{$\mathrm{H}_{2} \mathrm{SO}_{4}(2)$} & \multicolumn{2}{|c|}{$\mathrm{DC}^{(3)}$} & \multicolumn{2}{|c|}{ OXALATO $^{(4)}$} & \multicolumn{3}{|c|}{$F R X^{(5)}$} \\
\hline & & $\mathrm{Fe}$ & $\mathrm{Mn}$ & $\mathrm{Fe}$ & $\mathrm{Mn}$ & $\mathrm{Fe}$ & $\mathrm{Mn}$ & $\mathrm{Fe}$ & $\mathrm{Mn}$ & $\mathrm{Ce}$ \\
\hline & ----- m ----- & ------ & $-\cdots$ & $\begin{array}{l}----- \\
---1\end{array}$ & 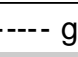 & ----- & 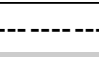 & - & ----- & $\mathrm{mg} \mathrm{kg}^{-1}$ \\
\hline A & $0-0,1$ & 20,07 & 0,31 & 6,52 & 0,12 & 0,75 & 0,10 & 18,33 & 0,34 & 63 \\
\hline$E$ & 0,26 & 15,59 & 0,31 & 8,70 & 0,11 & 0,71 & 0,08 & 19,16 & 0,31 & 78 \\
\hline Bt1 & 0,38 & 28,04 & 0,23 & 14,60 & 0,05 & 1,15 & 0,02 & 29,75 & 0,25 & 116 \\
\hline $\mathrm{Bt2}$ & 0,60 & 34,76 & 0,23 & 28,78 & 0,07 & 1,50 & 0,02 & 34,71 & 0,27 & 102 \\
\hline F-S & 0,85 & 41,12 & 0,23 & 33,23 & 0,05 & 1,86 & 0,01 & 48,45 & 0,38 & 154 \\
\hline F-N & 0,85 & 272,10 & 0,16 & 269,62 & 0,08 & 6,94 & 0,004 & 304,55 & 0,20 & 46 \\
\hline $\mathrm{Cf}$ & 1,10 & 91,68 & 0,39 & 86,84 & 0,10 & 2,42 & 0,07 & 85,49 & 0,49 & 217 \\
\hline $\mathrm{Cr}$ & 1,64 & 44,20 & 0,78 & 40,72 & 0,28 & 2,00 & 0,67 & 43,84 & 0,70 & 259 \\
\hline $\mathrm{R}$ & 1,90 & 55,80 & 0,93 & 40,80 & 0,90 & 2,17 & 1,54 & 51,56 & 1,06 & 134 \\
\hline
\end{tabular}

1)F-S: matriz interglebular do horizonte petroplíntico F; F-N: nódulos petroplínticios do horizonte $\mathrm{F}$.

(2) $\mathrm{H}_{2} \mathrm{SO}_{4}$ : ataque sulfúrico. Teores totais dos elementos na fração argila; (3)DC: extrator ditionito-citrato. Ferro e manganês livres; (4)OXALATO: extrator oxalato-oxálico. Ferro e manganês amorfos. ${ }^{(5)} \mathrm{FRX}$ : fluorescência de raios X. Teores totais dos elementos na amostra. 
A composição química e mineral dos nódulos manganíferos, bem como os mecanismos pedogenéticos enunciados acima, estão de acordo com a estabilidade termodinâmica da cerianita, a qual precipita quando condições oxidantes prevalecem (Braun, et al., 1990). Esse fato corrobora a suposição de que a gênese desses nódulos se deu sob condições mais oxidantes no perfil em relação aqueles essencialmente ferruginosos e que predominam no horizonte ferricrete. Por isso, estão localizados apenas na base do horizonte petroplíntico (Figura 2) e podem ser considerados os mais jovens deste horizonte.

\section{CONCLUSÕES}

- Acumulações localizadas de cério (Ce) foram encontradas apenas nos nódulos petroplínticos que apresentam revestimentos de óxidos de $\mathrm{Mn}$, situados na base do horizonte petroplíntico.

- Além de $\mathrm{Ce}$, o elemento cobalto (Co) também se concentra no interior dos nódulos ferro-manganíferos devido à ação co-precipitadora dos óxidos de manganês aí depositados.

- A presença de cerianita $\left(\mathrm{CeO}_{2}\right)$ no interior dos nódulos petroplínticos com núcleo enegrecido está associada ao rebaixamento definitivo do lençol freático, quando condições mais oxidantes prevaleceram em relação à gênese dos nódulos essencialmente ferruginosos.

\section{AGRADECIMENTOS}

Os autores agradecem os colegas da Estação Experimental de Pindorama, especialmente ao Dr. Antônio Lúcio Mello Martins e ao agrônomo Luís Cláudio Pallermo pelo auxílio nos trabalhos de campo. Ao Prof. Dr. Adolpho Jose Melfi, pelas facilidades concedidas no uso do microscópio eletrônico de varredura e análises com a microssonda do NUPEGEO/IAG/USP e ao técnico Hélder pela disposição, receptividade e manuseio do microscópico.
A)

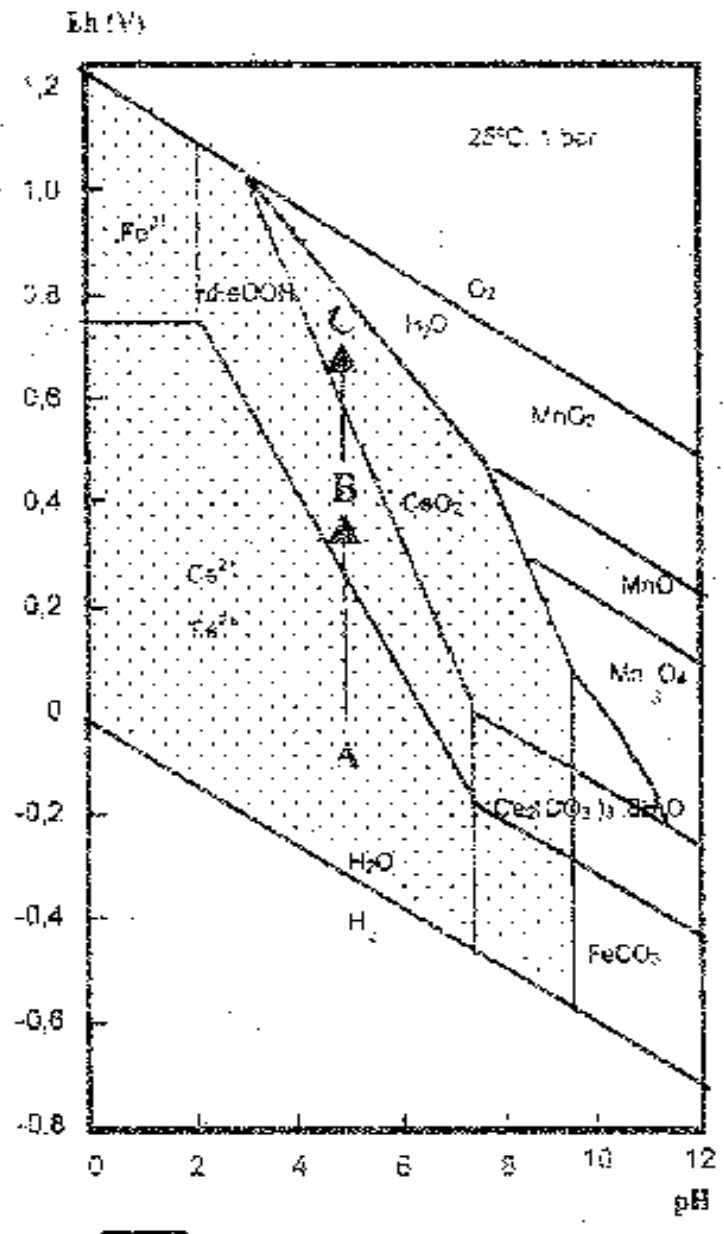

B)

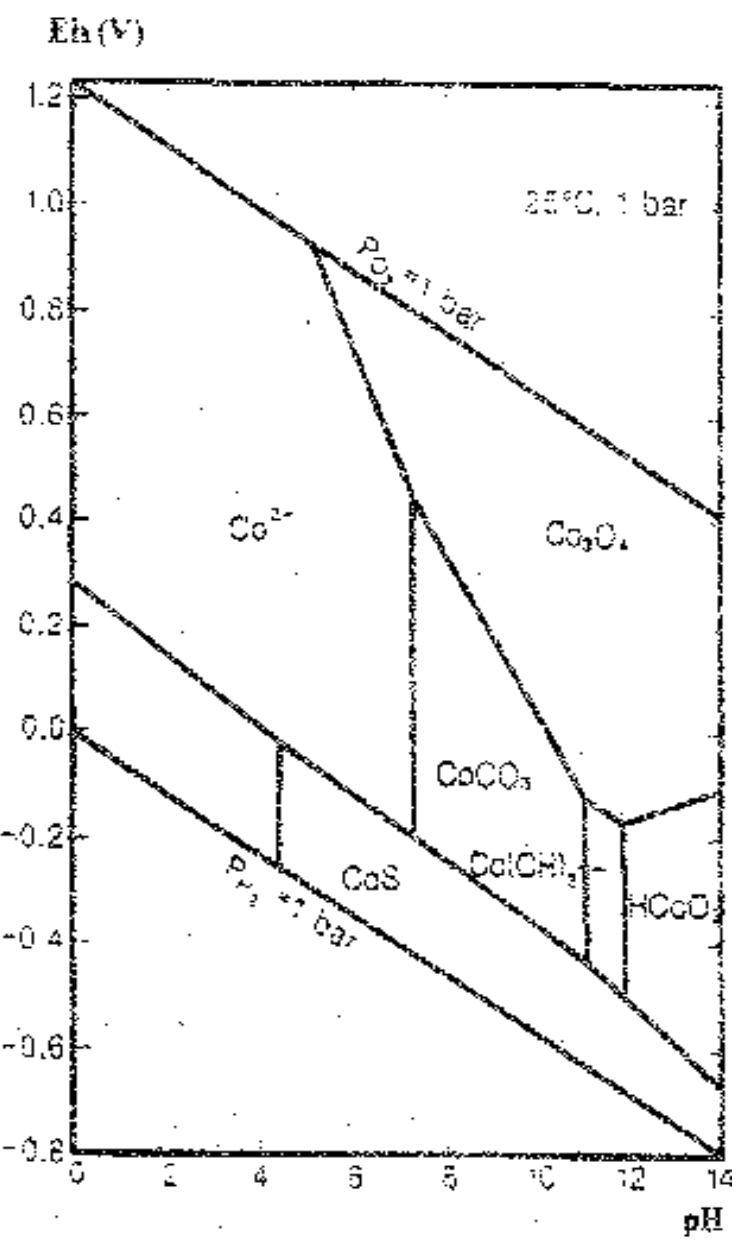

Figura 6 - A) Campos de estabilidade da cerianita $\left(\mathrm{CeO}_{2}\right)$, Ce-Lanthanida $\left(\mathrm{Ce}_{2}\left(\mathrm{CO}_{3}\right)_{3} \cdot 8 \mathrm{H}_{2} \mathrm{O}\right)$, goethita $(\mathrm{aFeOOH})$, siderita $(\mathrm{FeCO}), \mathrm{MnO}$, $\mathrm{MnO}_{2}$ e $\mathrm{Mn}_{2} \mathrm{O}_{3}$ estimados a partir da constante de equilíbrio log $\mathrm{K}_{0}$. Fonte: Adaptado de Braun et al. (1990). B) Diagrama de estabilidade de parte do sistema Co-S-C-H. Fonte: Brookins (1988). 


\section{REFERÊNCIAS BIBLIOGRÁFICAS}

BEAUVAIS, A.; BOEGLIN, J.L.; COLIN, F.; MAZALTARIM, D.; MULLER, J.C. Geochemical evolution and degeneration of ferricretes under a humid tropical climate in the east of Central African Republic. Chemical Geology: Geochemistry of the earth's surface and of mineral formation, v.84, p.25-26, 1990. Special Issue.

BEAUVAIS, A.; COLIN, F. Formation and transformation processes of iron duricrust systems in tropical humid environment. Chemical Geology, v.106, p.77-101, 1993.

BEAUVAIS, A.; ROQUIN, C. Petrological differentiation patterns and geomorphic distribuition of ferricretes in Central Africa. Geoderma, v.73, p.63-82, 1996.

BOUMA, J. Hydrology and soil genesis of soils with aquic moisture regimes. In: WILDING, L.P.; SMECK, N.E.; HALL, G.F (Ed.) Pedogenesis and soil taxonomy: I. Concepts and interactions. Netherlands: Elsevier Science, 1983. cap.9, p.253-281.

BOURMAN, R.P. Modes of ferricrete genesis: evidence from southeastern Australia. Zeitscherift Für Geomorphologie, v.37, p.77-101, 1993.

BRAUN, J.J.; PAGEL, M.; MULLER, J.P.; BILONG, P.; MICHARD, A.; GUILLET, B. Cerium anomalies in lateritic profiles. Geochimica et Cosmochimica Acta, v.54. p.7814-795, 1990.

BREWER, R. Fabric and mineral analysis os soils. New York: Robert E. Krieger, 1976. 482p.

BROOKINS, D.G. Eh-pH Diagrams for Geochemistry. Berlin: Springer Verlag, 1988. 176p.

BUURMAN, P.; LAGEN, B van; VELTHORST; E.J. Manual for soil and water analysis. Wageningen: Backhuys Publihers Leiden, 1996. 314p.

COELHO, M.R. Caracterização e gênese de ferricretes desenvolvidos do arenito Bauru, formação Adamantina (Ka), no município de Pindorama (SP). Piracicaba, 1998. 233p. Dissertação (Mestrado) - Escola Superior de Agricultura "Luiz de Queiroz", Universidade de São Paulo.

EMPRESA BRASILEIRA DE PESQUISA AGROPECUÁRIA. Sistema Brasileiro de Classificação de Solos. Brasília: EMBRAPA, 1999. 412p.

FRANZINI, M.; LEONI, L.; SAITA, M. A simple Method to evaluate the matrix effects in X-Ray fluorescence analysis. X-Ray Spectrometry, v.1, p.151-154, 1972
LEMOS, R.C. de; SANTOS, R.D. Manual de descrição e coleta de solo no campo. 3.ed. Campinas: Sociedade Brasileira de Ciência do Solo, 1996. 83p.

MAcKENZIE, R.M. Manganese oxides and hydroxides. In: : DIXON, J.B.; WEED, S.B. (Ed.) Mineral in soil environments. 2.ed. Madison: Soil Science Society of America, 1989. cap.9, p.439-461.

MILNES, A.R. ;BOURMAN, R.P.; NORTHCOTE, K.H. Field relationships of ferricretes and weathered zones in southern south Australia: A contribution to 'Laterite' studies in Australia. Australian Journal of Soil Research, v.23, p.441-465, 1985.

OLLIER, C.D. A. Laterite profiles, ferricrete and landscape evolution. Zeitscherift Für Geomorphologie, N.F., v.35, p.165-173, 1991.

PIPER, D.Z. Rare earth elements in ferromanganese nodules and other marine phases. Geochimica et Cosmochimica Acta, v.38, p.1007-1022, 1974.

RAIJ,B. van; VALADARES, J.M.A.S. Análise dos elementos maiores de rochas, argilas e solos. Campinas: IAC/Seção de Pedologia, Divisão de Solos, 1974. 23p. (Boletim Técnico, 16)

ROQUIN, C. Element distribuition patterns in laterites of southern Mali: consequence for geochemical prospecting and mineral exploration. Applied Geochemistry, v.5, p.303-315, 1990.

SOARES, P.C.; LANDIM, P.M.B.; FÚLFARO, V.J.; NETO SOBREIRO, A.F. Ensaio de caracterização estratigráfica do cretáceo no Estado de São Paulo: Grupo Bauru. Revista Brasileira de Geociências, v.10, p.177-235, 1980.

SOIL SURVEY STAFF. Department of Agriculture. Soil Conservation Service. 6.ed. Keys to soil taxonomy. Washington: USDA, 1994. 306p.

TAYLOR, R.M. The association of manganese and cobalt in soils - further observations. Journal of Soil Science, v.19, p.77-80, 1968.

TAYLOR, R.M.; MacKENZIE, R.M. The association of trace elements with manganese minerals in Australian soils. Australian Journal of Soil Research, v.2, p.235-248, 1966.

VETTORI, L. Métodos de análise de solos. Rio de Janeiro: EPE Ministério da Agricultura, 1969. 24p. (Boletim Técnico, 7).

$\overline{\text { Recebido em } 11.12 .98}$ 